\title{
Commitment and Relationship Maintenance Behaviors as Marital Protective Factors during Economic Pressure
}

Jeffrey P. Dew

Brigham Young University - Provo, jeff_dew@byu.edu

Mark Jackson

Follow this and additional works at: https://scholarsarchive.byu.edu/facpub

Part of the Other Social and Behavioral Sciences Commons

\section{Original Publication Citation}

Dew, J. P.,\& Jackson, M.* (2017). Commitment and relationship maintenance behaviors as marital protective factors during economic pressure. Journal of Family and Economic Issues, $39,191-204$.

\section{BYU ScholarsArchive Citation}

Dew, Jeffrey P. and Jackson, Mark, "Commitment and Relationship Maintenance Behaviors as Marital Protective Factors during Economic Pressure" (2017). Faculty Publications. 4537.

https://scholarsarchive.byu.edu/facpub/4537 


\title{
Commitment and Relationship Maintenance Behaviors as Marital Protective Factors during Economic Pressure
}

\author{
Jeffrey Dew ${ }^{1} \cdot$ Mark Jackson $^{2}$
}

Published online: 23 October 2017

(C) Springer Science+Business Media, LLC 2017

\begin{abstract}
Using a contemporary national sample of married couples ( $N=1368$ couples) and a dyadic path analysis, the authors examined whether commitment and relationship maintenance behaviors facilitate marital quality resilience for wives and husbands reporting recession-related financial stressors and economic pressure. Relationship maintenance behaviors moderated the association between economic pressure and marital quality for wives. Wives reported higher levels of marital satisfaction and lower levels of divorce proneness during economic pressure when husbands reported higher levels of relationship maintenance behaviors. Unexpectedly, wives reported higher levels of divorce proneness during economic pressure when husbands reported higher levels of marital commitment.
\end{abstract}

Keywords Commitment - Economic well-being $\cdot$ Marital quality $\cdot$ Relationship maintenance behaviors

\section{Introduction}

Researchers have linked negative economic stressors, and the feelings of economic pressure that they engender, to lower levels of marital quality (Conger et al. 1994). Furthermore, financial issues are among the most common issues

Jeffrey Dew

jeff_dew@byu.edu

Mark Jackson

Mark.Jackson@1dschurch.org

1 School of Family Life, Brigham Young University, Provo, UT, USA

2 The Church of Jesus Christ of Latter-day Saints, Salt Lake City, UT, USA over which couples fight (Papp et al. 2009; Stanley et al. 2002), and financial conflict evidences a stronger association with disrupted marital quality than conflict over other relationship issues (Dew et al. 2012; Papp et al. 2009). Given the association of economic stressors, feelings of economic pressure, and decreased marital quality (Conger et al. 1994), identifying protective factors that can help couples during economic pressure is important.

Unfortunately, few researchers have examined protective factors that can help couples maintain marital quality while experiencing economic stressors. We are aware of only four such studies. Results from these studies showed that problem solving skills (Conger et al. 1999), religious marital sanctification (Ellison et al. 2011), financial satisfaction (Archuleta et al. 2011), and a stable personality (Liker and Elder 1983) were associated with marital resilience during economic problems.

These four studies are foundational, but additional research is needed. That researchers have catalogued only four marital protective factors in the context of economic problems seems somewhat limited, given that many couples face such problems. Identifying additional factors that could help couples maintain their relationships when they experience feelings of economic pressure would benefit couples, researchers, and practitioners. Further, the four studies mentioned above used data that predate the 2007-2009 Recession, and given the salience of that period as it relates to couple economic wellbeing, using data collected after the Recession to carry out such an investigation would make a significant contribution to this body of literature. PostRecession data would be valuable in this context given that the Recession brought about both employment-related problems (like most past recessions have) and the unique stressor of housing-related problems. These data are situated within the aftermath of the 2007-2009 Recession, so as such, this 
study may give additional insight into how couples, on a micro-level, handle macro-economic downturns. Additionally, each of the four previous studies relied on data that had been collected in a single state. Finally, some of the studies used only individual data rather than dyadic data. This is problematic because spousal attitudes and behaviors might be as much a protective factor during stress as one's own attitudes and behaviors.

The current study fills some of these gaps. First, we examined new potential protective factors (i.e., marital commitment and relationship maintenance behaviors) that might facilitate more stable marital quality during economic pressure. Second, we used a recent (2010-2011), nationally representative sample of married couples $(N=1,368)$ to test our hypotheses. Third, because our data were dyadic, we could examine both the associations between participants' own reports and their marital quality (i.e., actor effects) and the associations between spouses' reports and participants' outcomes (i.e., partner effects; Kenny et al. 2006).

\section{Economic Stressors, Economic Pressure, and Marital Resilience}

Fundamentally, this is a study of marital resilience. Resilience is manifested in the presence of positive family outcomes or absence of negative family outcomes despite the presence of risk (Patterson 2002). Thus, marital resilience is apparent when, as a result of moderating or protective factors, reports of marital quality improve, remain stable, or more slowly deteriorate for some than for others during difficult conditions.

We combine two frameworks- the Family Stress Model of Economic Pressure and Marital Distress, or simply Family Stress Model (Conger et al. 1994), and the Family Adjustment and Adaptation Response (FAAR) model (Patterson 2002) — to generate our hypotheses. The Family Stress Model explains the interface of financial stressors and marital quality. The FAAR model is suited for examinations of family resilience (Patterson 2002).

\section{The Family Stress Model}

The Family Stress Model explains a process that leads from financial stressors to decreased marital quality. It begins with financial stressors such as job loss, low income, or other types of financial difficulties. These financial stressors begin to create feelings of economic pressure (Conger et al. 1994). Economic pressure is the perception that the family is struggling to meet material needs, and the stressful feelings that accompany this perception (e.g., Conger et al. 1994). In other words, easily quantifiable variables such as job loss, housing problems, or low income are objective financial stressors, whereas economic pressure represents the subjective perception and affective response to such stressors. When feelings of economic pressure exist, the Family Stress Model indicates that they lead to other types of negative affect such as anxiety, depression, and hostility (Conger et al. 1994). Finally, the model posits that these negative affective states are associated with decreased marital quality.

The 2007-2009 Recession created financial stressors for many American families. Over 8 million workers lost their jobs during the recession and the 6 months following it (Goodman and Mance 2011). These job losses hit most sectors of the economy, and the lengths of time that individuals spent unemployed were much greater, on average, than people experienced during previous recessions. Somewhat uniquely, many families also experienced housing problems. When the combination of the housing-value bubble and subprime mortgage lending expansion was no longer sustainable, many families either experienced stress because of their housing or lost their housing altogether. Banks began an estimated 8.2 million foreclosures between 2007 and 2011 and completed at least 4 million foreclosures during this time (Blomquist 2012).

Consequently, the Family Stress Model informs the first part of our conceptual model (Fig. 1). We hypothesize that wives and husbands who report employment and/or housing problems resulting from the recession will report greater economic pressure. Further, economic pressure will be indirectly associated with measures of marital quality such as satisfaction and divorce proneness. Economic pressure will mediate the association between the recession-related stressors and measures of marital quality.

\section{Integrating the Family Stress and FAAR Models}

Although the Family Stress Model explains the process through which financial stressors decrease marital quality, it does not explain how moderating factors might protect couples' relationships from economic pressure (Conger et al. 1999, is an exception). We reframe some of the concepts from the Family Stress Model within the FAAR model (Patterson 2002) to examine marital factors that might promote resilience. We do not discuss all of the aspects of the FAAR model; we present the aspects of the model that are most relevant to the present study and, importantly, those aspects that we can test, given our data.

Like the Family Stress Model, the concept of stressors is central to the FAAR model, but the FAAR model calls stressors "demands." The FAAR model proposes that demands or stressors prompt individuals and families to use their capabilities/resources to either regain homeostasis or create a new one (Patterson 2002). The objective financial stressors in the Family Stress Model are the demands in the FAAR model. 


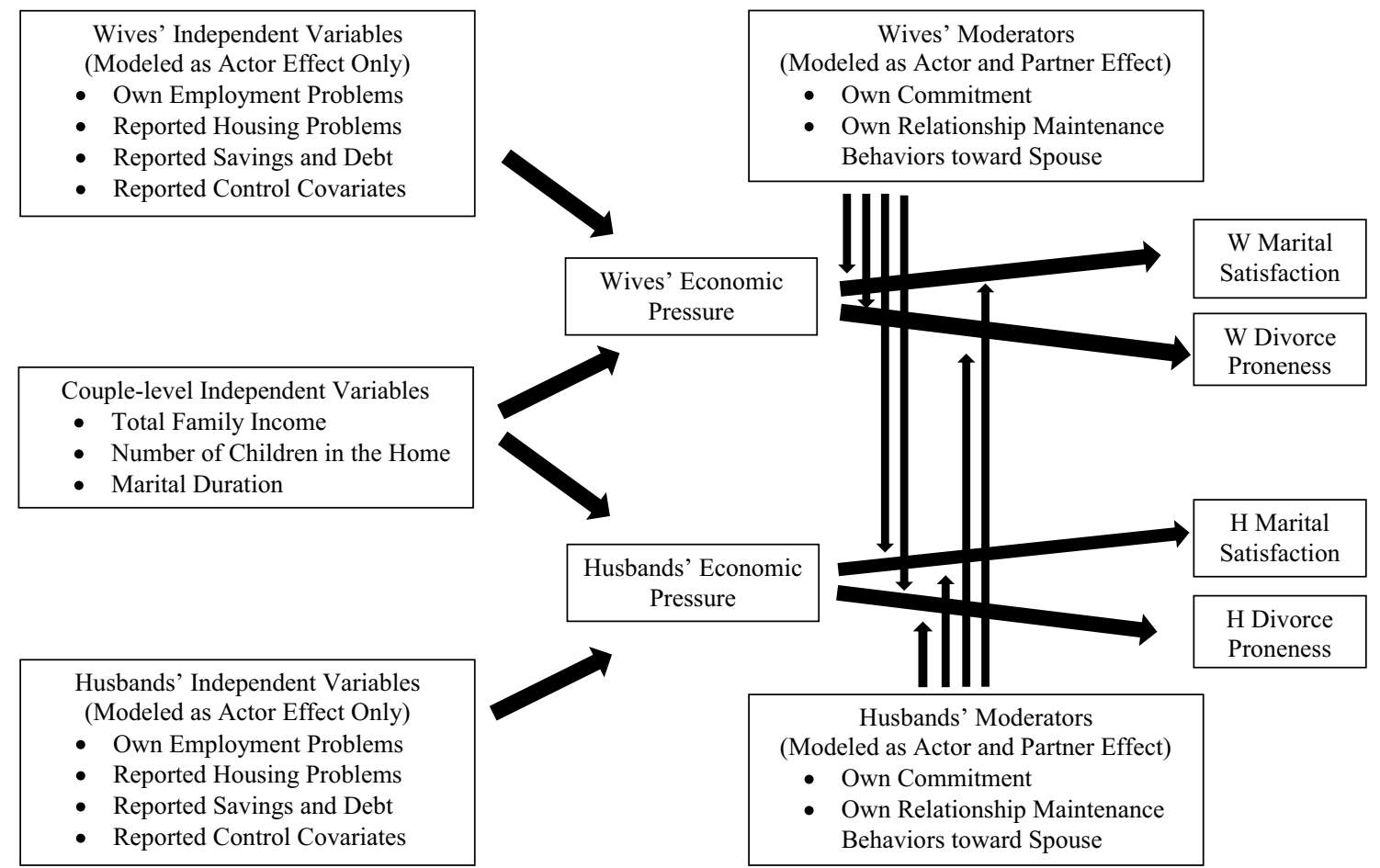

Fig. 1 Conceptual and analytic mediator/moderator model. (Note All of the participant's own independent variables were controlled for in the marital quality dependent variables.)

In the FAAR model, demands do not completely capture how individuals or families experience stress. In the model, the concept of "meanings" is important both prior to and following a crisis. Meanings are individuals' and families' subjective perceptions of both the demands they face and the capabilities that they possess to meet those demands (Patterson 2002). Families may, for example, reframe the meaning of their demands to adapt to a new situation and regain their family equilibrium.

Because economic pressure is a subjective view, then, the FAAR model might consider it to be a meaning. The crucial insight from the FAAR model regarding economic pressure, then, is that the more economic pressure spouses report, the more they have defined their financial circumstances as problematic for their family. The FAAR model might assert that this accounts for some of the strength of economic pressure to effect marital distress.

\section{Marital Capabilities and Resilience}

The FAAR model makes provisions for individuals and families to use their capabilities to directly adjust and adapt to life's demands. According to the model, resilient couples use their capabilities and resources to experience economic pressure without experiencing substantial declines in marital quality. Researchers have identified characteristics of couple resilience during economic pressure (Archuleta et al. 2011; Conger et al. 1999; Ellison et al. 2011; Liker and Elder 1983). Ellison et al. (2011), for example, observed that higher levels of religious marital sanctification were associated with lower levels of divorce proneness during financial strain. The authors of these studies speculated that the resilience factors allowed spouses to compartmentalize feelings of economic pressure to prevent it from spreading additional types negative affect (e.g., anxiety, hostility) to the relationship.

We study two additional concepts, dedication commitment and relationship maintenance behaviors, that may moderate the association between economic pressure and marital quality, but that research has not previously tested. We test these two concepts because of their relatively strong association with marital quality (e.g., Dainton 2000; Dew and Wilcox 2013; Stanley et al. 2010). Furthermore, commitment and relationship maintenance behaviors are accessible to all married couples. In previous studies, some of the moderating factors, like non-reactive personalities or religious marital sanctification, are not necessarily applicable to everyone. Any married individual, however, can adopt commitment attitudes and practice relationship maintenance behaviors on a regular basis.

Scholars have defined commitment as "the intention to maintain a relationship over time" (Stanley et al. 2010, p. 243). Two forms of commitment have received attention in the literature: dedication commitment and constraint 
commitment (Stanley and Markman 1992). We focus on dedication commitment because our data do not contain constraint commitment measures. We did not want to use proxies (e.g., shared number of friends, number of children in the home) that may or may not validly measure constraint commitment. Dedication commitment reflects a "desire of an individual to maintain or improve the quality of his or her relationship for the joint benefit of the participants" (Stanley and Markman 1992, p. 595).

Dedication commitment could help individuals avoid the declines in marital quality during economic pressure. Because it involves a pro-relationship mindset, dedication commitment may enable marital partners to look beyond current feelings of economic pressure and focus on longterm marital outcomes (Stanley et al. 2010).

One spouse's commitment might also help the other spouse during feelings of economic pressure. Commitment might work as a signaling mechanism that stabilizes the other spouse's marital quality during periods of economic pressure. For example, husbands' commitment might be associated with lower levels of wives' divorce proneness or higher levels of wives' marital satisfaction when wives report economic pressure because the wives know that their husbands are invested in the relationship.

For one's commitment to act as a signal to his or her spouse, the commitment may need to be demonstrated through behaviors. Research has indicated that even though dedication commitment is a long-term cognitive orientation toward a relationship, it also promotes behaviors that nurture relationships and help to fulfill the desire to stay together. For example, a study by social psychologists showed that commitment was positively associated with participants' willingness to compromise with their partners over time (Wieselquist et al. 1999). Thus, dedication commitment might motivate partners to engage in positive relationship behaviors that could stabilize or even enhance relationship quality during economically difficult times (Stanley and Markman 1992; Wilcox and Dew 2016).

Behaviors such as relationship compromise are known in social psychology as relationship maintenance behaviors. Individuals use these behaviors to maintain and strengthen their intimate relationships (Stafford and Canary 1991). They include such behavior as forgiving, talking about the relationship itself, and offering assurances (Stafford 2011). Not surprisingly, studies have shown that relationship maintenance behaviors are positively associated with relationship quality (Dainton 2000; Dew and Wilcox 2013; Stafford 2003).

When one spouse engages in relation maintenance behaviors, it may protect the other spouse's marital quality during economic pressure. One spouse's relationship maintenance behaviors signal that spouse's intention to continue in the relationship and may reduce marital distress or worries of divorce during times of economic pressure. Such behaviors might also simply make the relationship more enjoyable (Dew and Wilcox 2013; Stafford 2003). Receiving relationship maintenance behaviors from one's spouse, then, may reduce the association between economic pressure and marital quality.

Finally, participants' own reports of relationship maintenance behaviors might also moderate the relationship between economic pressure and declines in their own marital quality. Previous research suggested that one's own relationship maintenance behaviors were positively associated with marital quality even when one's spouse's relationship maintenance behaviors were also in the same multivariate model (Dew and Wilcox 2013). These findings suggest that one's own relationship maintenance behaviors may be associated with relationship quality gains.

\section{Actor-Partner Interdependence Model}

Because we suggest that participants' commitment or relationship maintenance behaviors might moderate the relationship between economic pressure and marital quality either for themselves or their spouses, and because our data were dyadic, we used the Actor Partner Interdependence Model (APIM, Kenny et al. 2006; Fig. 1) as an analytic framework. The APIM tests actor effects (i.e., the association between a participant's own independent and dependent variables) and partner effects (i.e., the association between a participant's independent variables and his or her spouse's dependent variables).

\section{Contextual Issues}

In addition to these hypotheses and variables, we controlled for basic demographic covariates and couples' financial situations. We controlled for basic demographic characteristics (e.g., education, race) to help account for social structural issues that might be conflated with economic pressure out of the model. We also controlled for couples' financial situations (i.e., income, assets, consumer debt) so that the association between economic pressure, the moderators, and marital quality can be assessed net of the couples' actual financial positions.

\section{Summary}

To summarize, the Family Stress Theory suggests that financial problems can harm marriages (Conger et al. 1994), but the FAAR model suggests that couples' demands can be tempered by their capabilities and the meanings they attribute to stressors (Patterson 2002). This study contributes to the literature by testing whether relationship-specific capabilities, such as commitment and relationship maintenance 
behaviors, moderate the association between feelings of economic pressure and marital quality. It also adds to the literature by using nationally-representative dyadic datadata qualities which none of the other studies of these associations have had.

\section{Method}

\section{Data and Sample}

Data for this research came from the Survey of Marital Generosity (SMG). The SMG was originally designed to measure a broad range of marital attitudes, behaviors, and outcome variables. It also included financial and demographic questions. The SMG was intended to be a national sample of heterosexual married couples with participants aged 18-45.

A survey research firm (Knowledge Networks) conducted the SMG from late 2010 to early 2011. To gather the data for the SMG, the firm invited participants from their preexisting Knowledge Panel who were married and between the ages of 18 and 45; spouses of the participants could be between the ages of 18 and 55. The original Knowledge Panel was nationally representative and obtained using random-digit dialing and random-address-based sampling. By using random-address-based sampling, the survey included individuals without landline-based phone numbers and thus avoided a common contributor to sampling bias.

All of the couples in the SMG were married. Participants completed the survey over the internet. If participants did not have an internet connection, Knowledge Networks provided the connection. A total of 4510 individuals from the original Knowledge Panel were invited to participate in the SMG, and 3455 completed the survey (1745 wives and 1705 husbands).

We utilized two inclusion criteria to determine which SMG participants were eligible for the present study. First, to be included in this study, SMG participants had to have a spouse who also completed the survey. This was necessary to conduct the analysis using the APIM model. Most SMG participants (89\%) had participating spouses. Second, both spouses had to be between the ages of 18 and 45 ; these were the only individuals with post-stratification weights. Utilizing these two criteria yielded a sample of 1368 wives and 1368 husbands.

We examined the differences between those included in this study and those excluded by our criteria. Participants in our study reported slightly higher marital satisfaction than those who were excluded $(r=.05, p<.05$ for both wives and husbands). None of the other variables regarding marriage (e.g., divorce proneness, commitment, etc.) were significantly different between the two groups. Those included in this study reported slightly lower savings levels $(r=-.12$, $p<.001)$. Furthermore, Hispanic men were slightly more likely to be eligible for this study $(r=.06, p<.001)$ than White, non-Hispanic men. Those with lower household incomes $(r=-.07, p<.01)$, though not more economic pressure, were slightly more likely to be eligible for this study. Finally, both wives $(r=-.39, p<.001)$ and husbands $(r=-.52, p<.001)$ who were able to be in this study were younger than those who were not. This last finding was not surprising given that we could not accommodate those older than 45 years old because they did not have post-stratification weights.

\section{Measures}

\section{Dependent Variables}

We used a marital satisfaction scale as one measure of marital quality. We created this scale by taking the mean of four items that surveyed participants' happiness in marriage. These items pertained to love and affection, fairness, communication, and sex. For each of these items, participants rated their level of happiness on a scale of 1 (Very Unhappy) to 5 (Very Happy). Cronbach's alpha was 0.88 for wives and 0.86 for husbands.

The second measure of marital quality was a single-item variable of participants' perceived divorce proneness. Participants rated the level of likelihood that they would divorce on a scale of 1 (Very Low) to 11 (Very High). Because of the heavy positive skew of this variable, we top-coded it at 4.

\section{Independent and Moderator Variables}

We used two variables to measure recession-related employment and housing problems. The employment question asked, "Have you been unemployed, had your pay cut, or had your work hours reduced since the recession began?" The housing question asked, "Have you been through a foreclosure or had problems making mortgage payments since the recession began?" Respondents answered "Yes" or "No" to each question. We dummy-coded these variables.

Economic pressure was a moderator variable in our analyses (Fig. 1). We operationalized this construct using an item that asked, "How often do you worry that your total family income will not be enough to meet your family's expenses and bills?" Participants could respond from 1 (Never) to 5 (Almost all of the time). We centered this variable (and all other moderator variables) around its mean prior to creating interaction terms.

Reported relationship maintenance behaviors also functioned as a moderator variable. We measured these behaviors using the mean of four items indicating how often participants engaged in small acts of kindness for their spouses, expressed affection, expressed respect, and forgave their 
spouses. Participants rated the frequency with which they engaged in those behaviors on a scale of 1 (Never) to 5 (Always). These items, while not nearly as numerous as the items included in Stafford's (2011) Relationship Maintenance Behavior Measure, capture some of the same dimensions within that measure. For this scale, Cronbach's alpha was 0.85 for wives and 0.84 for husbands. Factor analysis of these items in previous studies has indicated that one factor explains most of the variance in the items (Dew and Wilcox 2013).

We created the commitment variable by taking the mean of four items from the personal dedication subscale of Stanley and Markman's (1992) Commitment Inventory (e.g., "I want this relationship to stay strong no matter what rough times we encounter"). Participants rated their level of agreement with each item on a scale of 1 (Strongly Disagree) to 5 (Strongly Agree). For this scale, Cronbach's alpha was 0.82 for wives and 0.83 for husbands.

We used two measures of financial wellbeing to examine participants' financial contexts: liquid savings and consumer $\mathrm{debt}^{1}$. To measure liquid savings, we asked participants, "What is the approximate total value of your savings, including things like savings accounts, money market shares, and CD's?" We measured consumer debt by asking, "How much debt do you owe on credit card or charge accounts, installment loans, or bills that you've owed for over 2 months? Do not include vehicle loans or home mortgage debt." Both items had a response scale of 1 (None) to 12 (\$250,000 or more). Given the wording of these items, we were not sure whether participants reported individual-level or householdlevel savings and debt. Because of this problem, we included the reports of savings and debt as actor, but not partner, effects.

Finally, we included participants' education, total household income, number of children in the home, marital duration, number of marriages, and race/ethnicity as control covariates in all of the models. We measured education on a scale of 1 (No Formal Education) to 14 (Professional or Doctorate degree). Total household income ${ }^{2}$ was reported on a scale of 1 (Less than $\$ 5,000$ ) to 19 ( $\$ 175,000$ or more). Participants reported the total number of children in the home and their marital duration in years. These variables were couple-level variables, and strong agreement was reported between spouses (the correlations for these two variables were at or near 1) so we simply used wives' reports of these variables in the models. Each participant reported the number of times he or she had been married. Participants reported their race/ethnicity. From these responses, we created three dichotomous variables: Black non-Hispanic,

\footnotetext{
1 These two variables were measured in US dollars.

2 This variable was also measured in US dollars.
}

Hispanic, and Other; White, Non-Hispanic was the omitted category.

\section{Analysis}

We used path analyses to test the model (Fig. 1). Path analyses allowed us to simultaneously test all of the pathways specified in the model. Furthermore, not only did it allow us to simultaneous test the mediation aspect of the model, but we were also able to test the moderation aspect (i.e., we were able to add the interaction terms to the model). Using a structural model to simultaneously test multiple regression pathways is the most common way of testing the Family Stress Model (e.g., Conger et al. 1999).

We could not use structural equation modeling, which essentially combines a structural model with a measurement model (conceptually equivalent to a factor analysis), because some of the major variables (e.g., economic pressure, divorce proneness) and most of the control variables were single-item measures. Scholars typically do not run factor analysis with only single-item variables. And although it is possible to specify measurement models with single items, such a solution also requires that the researcher estimate, the percent of measurement error variance in each single-item variable (Kline 2005). We did not believe that it was advisable to estimate - or simply guess - the percent of measurement error for the majority of the variables in our model.

The path models assumed that the variables, especially the dependent variables, were normally distributed. The divorce proneness variable was heavily skewed. To ensure that our findings were not influenced by this skewness, we tested models using non-linear transformations of the divorce proneness variable. The transformation that made divorce proneness most closely approximate the normal distribution was to top-code it. Any score of divorce proneness that exceeded four was set to four. The findings from this top-coded analysis were similar to the findings using the non-transformed variable. The few differences that arose were primarily in the control-variable coefficients. The only substantive difference was that wives' relationship maintenance behaviors predicted wives' and husbands' divorce proneness in the top-coded models, but not in the models with the non-transformed divorce proneness. Furthermore, the interaction between wives' economic pressure and husbands' commitment was statistically related with divorce proneness in the top-coded model, but the interaction only attained near-significance in the non-transformed divorce proneness models. We present the top-coded models given that they more closely meet the analytic assumptions of our models.

We used the provided post-stratification weights to make our findings representative. We were confronted 
Table 1 Descriptive statistics

\begin{tabular}{|c|c|c|c|c|c|c|}
\hline & \multicolumn{3}{|l|}{ Wives } & \multicolumn{3}{|c|}{ Husbands } \\
\hline & $M$ or $\%$ & StD & Range & $M$ or $\%$ & StD & Range \\
\hline Marital satisfaction & 3.81 & 0.92 & $1-5$ & 3.85 & 0.90 & $1-5$ \\
\hline Divorce proneness & 2.03 & 1.21 & $1-4$ & 2.00 & 1.20 & $1-4$ \\
\hline Economic pressure & 3.04 & 1.21 & $1-5$ & 2.95 & 1.24 & $1-5$ \\
\hline Commitment & 4.24 & 0.71 & $1-5$ & 4.25 & 0.70 & $1-5$ \\
\hline Relationship maintenance behaviors & 3.96 & 0.75 & $1-5$ & 3.89 & 0.78 & $1-5$ \\
\hline Consumer debt & 3.71 & 2.37 & $1-12$ & 3.67 & 2.35 & $1-12$ \\
\hline Savings & 4.74 & 3.15 & $1-12$ & 4.94 & 3.21 & $1-12$ \\
\hline Education & 10.65 & 1.90 & $3-14$ & 10.55 & 1.90 & $1-14$ \\
\hline Household income $^{\mathrm{a}}$ & 12.83 & 3.77 & $1-19$ & 12.83 & 3.77 & $1-19$ \\
\hline Number of children in home ${ }^{a}$ & 1.68 & 1.35 & $0-11$ & 1.68 & 1.35 & $0-11$ \\
\hline Marital duration ${ }^{\mathrm{a}}$ & 9.87 & 6.27 & $0-26$ & 9.87 & 6.27 & $0-26$ \\
\hline Number of marriages & 1.14 & 0.57 & $1-20$ & 1.18 & 1.05 & $1-20$ \\
\hline Black, non-Hispanic & $6.4 \%$ & & & $7.8 \%$ & & \\
\hline Hispanic & $15.6 \%$ & & & $16.5 \%$ & & \\
\hline Other & $9.0 \%$ & & & $8.0 \%$ & & \\
\hline
\end{tabular}

${ }^{\text {a }}$ These were couple-level variables

with the dilemma that weights were created at an individual level, but that our analysis was conducted on a dyadic level. We averaged wives' and husbands' weights to address this issue (the correlation between wives' and husbands' weights was $r=.63$ ). An analysis showed that the results using the averaged weights were not very different from models using either the wives' or the husbands' post-stratification weights. We also examined whether using the weights changed the results. Most of the results were similar, though some of the control covariate coefficients changed significance. Like the topcoded model, the interaction between wives' economic pressure and husbands' commitment was only statistically related with divorce proneness in the weighted models.

Missing data were the final analytical issue. The variables had between $0-2 \%$ of the cases missing, with a cumulative total of $5.3 \%$ of the sample $(n=73)$ missing at least one of the variables we intended to use in the models. We used full information maximum likelihood (FIML) techniques to obviate the problem of missing data. FIML yields estimates that are similar to multiple imputation (Johnson and Young 2011). We compared the FIML results to those obtained by using listwise deletion. Given the large sample size and the small number of missing variables, the findings from the FIML analysis were understandably the same as the findings obtained by using listwise deletion, with the exception of a few minor differences in the control covariate coefficients. We present the FIML findings.

\section{Results}

\section{Descriptive Statistics}

Table 1 shows the descriptive statistics. On average, participants were satisfied in their marriages $(M=3.81$ for wives, $M=3.85$ for husbands) and had low to moderate levels of divorce proneness ( $M=2.03$ for wives, $M=2.00$ for husbands). The mean of economic pressure was approximately at the scale's midpoint ( $M=3.04$ for wives, $M=2.95$ for husbands). Participants reported a relatively high average level of relationship maintenance behavior $(M=3.96$ for wives, $M=3.89$ for husbands) toward spouses and a high average level of commitment ( $M=4.24$ for wives and 4.25 for husbands). Mean education ( $M=10.65$ for wives, $M=10.55$ for husbands) corresponded to a level between having had some college but no degree and having an associate's degree. Finally, mean household income $(M=12.83)$ corresponded to a level between the $\$ 50,000$-to- $\$ 59,999$ level (i.e., an income score of 12) and the $\$ 60,000$-to- $\$ 74,999$ level (i.e., an income score of 13). The descriptive statistics for the additional control covariates are shown in Table 1.

We checked the demographic characteristics against data from the General Social Survey (GSS) to examine the representativeness of our sample. We restricted this analysis to married, 18- to 45-year-old individuals from the 2010 GSS to match our study. The participants in our study had the same education levels as those in the GSS. The average income for the participants in the GSS was $\$ 60,034$. Our 
Table 2 Path Model estimates of the association between financial wellbeing, commitment, relationship maintenance behaviors, economic pressure and marital satisfaction

\begin{tabular}{|c|c|c|c|c|c|c|c|c|}
\hline & \multicolumn{2}{|c|}{$\begin{array}{l}\text { Wives' Economic } \\
\text { Pressure }\end{array}$} & \multicolumn{2}{|c|}{$\begin{array}{l}\text { Husbands' Eco- } \\
\text { nomic Pressure }\end{array}$} & \multicolumn{2}{|c|}{$\begin{array}{l}\text { Wives' Marital } \\
\text { Satisfaction }\end{array}$} & \multicolumn{2}{|c|}{$\begin{array}{l}\text { Husbands' Mari- } \\
\text { tal Satisfaction }\end{array}$} \\
\hline & $b$ & $S E$ & $b$ & $S E$ & $b$ & $S E$ & $b$ & $S E$ \\
\hline Intercept & 0.26 & 0.29 & $0.82 * *$ & 0.28 & $4.01 * * *$ & 0.14 & $4.10 * * *$ & 0.18 \\
\hline Participant reports recession-related employment problems ${ }^{\mathrm{a}}$ & $0.20 * *$ & 0.07 & $0.22 * *$ & 0.07 & $-0.10^{*}$ & 0.05 & 0.03 & 0.05 \\
\hline Participant reports recession-related housing problems ${ }^{\mathrm{a}}$ & $0.32 *$ & 0.12 & $0.29 *$ & 0.12 & -0.16 & 0.09 & -0.09 & 0.08 \\
\hline W Economic pressure ${ }^{\mathrm{a}}$ & - & - & - & - & $-0.09 * * *$ & 0.02 & - & - \\
\hline W Marital commitment & - & - & - & - & $0.48 * * *$ & 0.05 & $0.11 *$ & 0.05 \\
\hline W Rel. maintenance behaviors & - & - & - & - & $0.28 * * *$ & 0.04 & $0.29 * * *$ & 0.04 \\
\hline $\mathrm{H}_{\text {Economic pressure }}^{\mathrm{a}}$ & - & - & - & - & - & - & $-0.10 * * *$ & 0.02 \\
\hline H Marital commitment & - & - & - & - & 0.04 & 0.04 & $0.39 * * *$ & 0.05 \\
\hline H Rel. maintenance behaviors & - & - & - & - & $0.28 * * *$ & 0.04 & $0.25 * * *$ & 0.04 \\
\hline Participant reported consumer debt ${ }^{\mathrm{a}}$ & $0.14 * * *$ & 0.02 & $0.13 * * *$ & 0.02 & $-0.03 * *$ & 0.01 & $-0.02 *$ & 0.01 \\
\hline Participant reported liquid savings ${ }^{\mathrm{a}}$ & $-0.10 * * *$ & 0.01 & $-0.07 * * *$ & 0.01 & -0.01 & 0.01 & $0.02 *$ & 0.01 \\
\hline Participant education $^{\mathrm{a}}$ & 0.02 & 0.02 & -0.03 & 0.02 & -0.01 & 0.01 & -0.02 & 0.02 \\
\hline Total family income ${ }^{\mathrm{b}}$ & $-0.05 * * *$ & 0.01 & $-0.06 * * *$ & 0.02 & -0.01 & 0.01 & -0.01 & 0.01 \\
\hline Number of children in home ${ }^{b}$ & $0.05^{*}$ & 0.02 & 0.05 & 0.03 & 0.02 & 0.02 & 0.01 & 0.02 \\
\hline Marital duration $^{\mathrm{b}}$ & 0.01 & 0.01 & 0.01 & 0.01 & 0.01 & 0.01 & -0.01 & 0.01 \\
\hline Participant number of marriages ${ }^{a}$ & 0.01 & 0.06 & -0.01 & 0.01 & -0.05 & 0.03 & 0.01 & 0.01 \\
\hline Participant Black, non-Hispanic ${ }^{a}$ & -0.06 & 0.15 & $0.46^{* * *}$ & 0.16 & 0.08 & 0.11 & 0.11 & 0.08 \\
\hline Participant Hispanic $^{\mathrm{a}}$ & -0.13 & 0.10 & $-0.22 *$ & 0.11 & 0.06 & 0.06 & $0.23 * * *$ & 0.07 \\
\hline Participant other race/ethnicity ${ }^{\text {a }}$ & 0.07 & 0.10 & 0.03 & 0.14 & -0.08 & 0.09 & 0.13 & 0.08 \\
\hline Participant economic pressure * participant commitment & - & - & - & - & 0.01 & 0.04 & 0.01 & 0.04 \\
\hline Participant economic pressure $*$ participant rel. maint. beh & - & - & - & - & -0.03 & 0.03 & 0.01 & 0.03 \\
\hline Participant economic pressure $*$ spouse commitment & - & - & - & - & -0.03 & 0.04 & -0.02 & 0.04 \\
\hline Participant economic pressure $*$ spouse rel. maint. beh & - & - & - & - & $0.09 * *$ & 0.03 & 0.05 & 0.03 \\
\hline $\mathrm{R}^{2}$ & 0.28 & & 0.26 & & 0.53 & & 0.48 & \\
\hline
\end{tabular}

$\mathrm{CFI}=0.96, \mathrm{RMSEA}=0.03, \mathrm{SRMR}=.01$

$* p<.05 ; * * p<.01 ; * * * p<.001$

${ }^{a}$ Only actor effects were modeled with these variables.

${ }^{\mathrm{b}}$ These were couple-level variables

income scale was not able to be that precise, but the mean of 12.83 on our income scale would likely be near $\$ 60,000$. The number of children in the GSS was 1.70 for men and 1.89 for women. In our study it was 1.68 . The GSS did not measure the current marital duration, so we were unable to compare our sample's marital duration against the GSS. Finally, we compared the race/ethnicity percentages in this study to the GSS. In our study, $6.4 \%$ of the wives identified as Black, non-Hispanic, $15.6 \%$ identified as Hispanic, and $9 \%$ identified as being in the other race/ethnic category. The GSS had 9.1, 16.7, and $6.6 \%$ of the wives in those same categories, respectively. Among the men in our study, 7.8\% identified as Black, non-Hispanic, $16.5 \%$ identified as Hispanic, and $8.0 \%$ identified themselves as being in the other race/ethnic category. The GSS had 4.1, 16.3, and $2.7 \%$ in those same categories, respectively. Thus, after using the post-stratification weights, our sample is close to the GSS sample, with the exception of some slight differences in race/ ethnicity composition.

\section{Path Model Results}

\section{Marital Satisfaction}

Table 2 shows the estimates from the path models regarding both economic pressure and marital satisfaction. Overall model fit was strong. The CFI was 0.96. The RMSEA was 0.03 , and the SRMR was 0.01 .

Because we presumed that economic pressure predicted marital satisfaction as a mediator variable in the path models, we discuss it first. The first and second columns in Table 2 show the associations between the independent variables and wives' and husbands' reports of economic pressure (respectively). As expected, wives' reports of 
Fig. 2 Wives' predicted marital satisfaction based on the wives' economic pressure by husbands' relationship maintenance behavior interaction

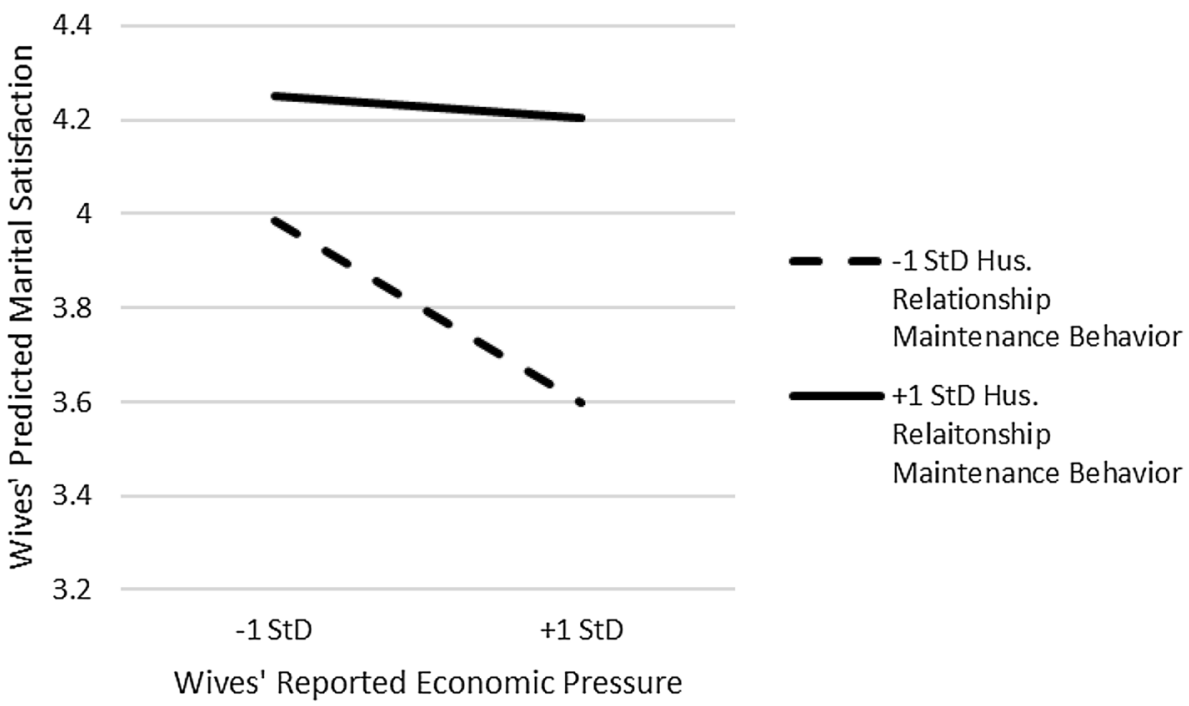

recession-related employment problems $(b=0.20, p<.01)$ and housing problems $(b=0.32, p<.05)$ were positively associated with their reports of economic pressure. Wives' reports of consumer debt were positively associated with economic pressure $(b=0.13, p<.001)$, while liquid savings $(b=-0.10, p<.001)$ and income $(b=-0.05, p<.001)$ were negatively associated. None of the other independent variables were associated with wives' reports of economic pressure. The model explained $28 \%$ of the variance in wives' reports of economic pressure.

The model for husbands' reports of economic pressure were similar. Husbands' reports of their own recessionrelated employment $(b=0.22, p<.01)$ and housing problems $(b=0.29, p<.05)$ were positively associated with their reports of economic pressure. Like wives, husbands' reported consumer debt was positively related to reports of economic pressure $(b=0.13, p<.001)$, but liquid savings $(b=-0.07, p<.001)$ and income $(b=-0.06, p<.001)$ were negatively related. Black, non-Hispanic husbands reported greater economic pressure than White, non-Hispanic husbands ( $b=0.46, p<.001)$, while Hispanic husbands reported less pressure $(b=-0.22, p<.05)$. The model explained $26 \%$ of the variance in husbands' reports of economic pressure.

Table 2 also shows the estimates for wives' and husbands' marital satisfaction. Contrary to the mediation we had predicted, wives' reports of recession-related employment problems were directly and negatively associated with their reports of marital satisfaction $(b=-0.10, p<.05)$. Wives' reports of economic pressure were negatively associated with their reports of marital satisfaction $(b=-0.09$, $p<.001)$. Wives' marital commitment $(b=0.48, p<.001)$, their reports of relationship maintenance behaviors toward their husbands $(b=0.28, p<.001)$, and husbands' reports of relationship maintenance behaviors toward their wives ( $b=0.28, p<.001)$ were positively associated with wives' reports of marital satisfaction. Wives' consumer debt was negatively associated with their marital satisfaction $(b=-0.03, p<.01)$.

Finally, an interaction emerged between wives' economic pressure and husbands' relationship maintenance behaviors $(b=0.09, p<.01)$. We graphed predicted levels of wives' marital satisfaction by entering \pm 1 standard deviation values for wives' economic pressure and \pm 1 husbands' relationship maintenance behavior values. This resulted in four different levels of wives' predicted marital satisfaction (Fig. 2). Among the group of wives whose husbands reported higher levels of relationship maintenance behaviors $(+1$ standard deviation), the difference between the wives with low economic pressure ( -1 standard deviation) and high economic pressure (+ 1 standard deviation) was only 0.05 of a point. In contrast, among the group of wives with husbands who reported less relationship maintenance behavior ( -1 standard deviation), the marital satisfaction difference between the low economic pressure wives $(-1$ standard deviation) and the high economic pressure wives (+ 1 standard deviation) was about 0.4 of a point. The overall model explained $53 \%$ of wives' marital satisfaction.

The results for husbands' reported marital satisfaction are also found in Table 2. Husbands' reported economic pressure was negatively associated with their reports of marital satisfaction $(b=-0.10, p<.001)$, but neither of the recession-related stressors was associated with marital quality when economic pressure was in the model. Husbands' own reported marital commitment $(b=0.39, p<.001)$ and relationship maintenance behaviors $(b=0.25, p<.001)$ were positively associated with their marital satisfaction. Like the wives' model, some partner effects emerged as well. Wives' reported marital commitment $(b=0.11, p<.05)$ and relationship maintenance behaviors $(b=0.29, p<.001)$ were also associated with husbands' reported marital satisfaction. 
Table 3 Path Model estimates of the association between financial wellbeing, commitment, relationship maintenance behaviors, economic pressure and divorce proneness

\begin{tabular}{|c|c|c|c|c|c|c|c|c|}
\hline & \multicolumn{2}{|c|}{$\begin{array}{l}\text { Wives' economic } \\
\text { pressure }\end{array}$} & \multicolumn{2}{|c|}{$\begin{array}{l}\text { Husbands' eco- } \\
\text { nomic pressure }\end{array}$} & \multicolumn{2}{|c|}{$\begin{array}{l}\text { Wives' divorce } \\
\text { proneness }\end{array}$} & \multicolumn{2}{|c|}{$\begin{array}{l}\text { Husbands' } \\
\text { divorce proneness }\end{array}$} \\
\hline & $b$ & $S E$ & $b$ & $S E$ & $b$ & $S E$ & $b$ & $S E$ \\
\hline Intercept & 0.27 & 0.29 & $0.82 * *$ & 0.28 & $1.97 * * *$ & 0.23 & $2.27 * * *$ & 0.22 \\
\hline Participant reports recession-related employment problems ${ }^{\mathrm{a}}$ & $0.20 * *$ & 0.07 & $0.21 * *$ & 0.07 & 0.10 & 0.06 & 0.10 & 0.06 \\
\hline Participant reports recession-related housing problems ${ }^{\mathrm{a}}$ & $0.32 *$ & 0.12 & $0.29 *$ & 0.12 & $0.27 * *$ & 0.10 & 0.16 & 0.11 \\
\hline W Economic pressure & - & - & - & - & $0.06 *$ & 0.03 & - & - \\
\hline W Marital commitment & - & - & - & - & $-0.76^{* * *}$ & 0.06 & $-0.24 * * *$ & 0.07 \\
\hline W Rel. maintenance behaviors & - & - & - & - & $-0.18 * * *$ & 0.05 & $-0.20 * * *$ & 0.06 \\
\hline H Economic pressure & - & - & - & - & - & - & $0.09 * *$ & 0.03 \\
\hline H Marital commitment & - & - & - & - & $-0.22 * * *$ & 0.06 & $-0.65 * * *$ & 0.07 \\
\hline H Rel. maintenance behaviors & - & - & - & - & $-0.22 * * *$ & 0.05 & $-0.20 * * *$ & 0.06 \\
\hline Participant reported consumer debt ${ }^{\mathrm{a}}$ & $0.14 * * *$ & 0.02 & $0.13 * * *$ & 0.02 & 0.02 & 0.02 & 0.01 & 0.01 \\
\hline Participant reported liquid savings ${ }^{\mathrm{a}}$ & $-0.10 * * *$ & 0.01 & $-0.07 * * *$ & 0.01 & -0.01 & 0.01 & -0.02 & 0.02 \\
\hline Participant education $^{\mathrm{a}}$ & 0.02 & 0.02 & -0.03 & 0.02 & 0.02 & 0.02 & -0.01 & 0.02 \\
\hline Total family income ${ }^{b}$ & $-0.06^{* * *}$ & 0.01 & $-0.06^{* * *}$ & 0.02 & -0.01 & 0.01 & -0.01 & 0.01 \\
\hline Number of children in home ${ }^{b}$ & $0.05 *$ & 0.02 & 0.05 & 0.03 & -0.04 & 0.03 & $-0.06^{*}$ & 0.03 \\
\hline Marital duration ${ }^{\mathrm{b}}$ & 0.01 & 0.01 & 0.01 & 0.01 & -0.01 & 0.01 & -0.01 & 0.01 \\
\hline Participant number of marriages ${ }^{a}$ & 0.01 & 0.06 & -0.01 & 0.01 & -0.01 & 0.04 & -0.02 & 0.03 \\
\hline Participant Black, non-Hispanic ${ }^{a}$ & -0.06 & 0.15 & $0.46 * * *$ & 0.16 & $0.51 * * *$ & 0.13 & $0.31 * *$ & 0.11 \\
\hline Participant Hispanic $^{\mathrm{a}}$ & -0.13 & 0.10 & $-0.22 *$ & 0.11 & 0.04 & 0.10 & -0.02 & 0.10 \\
\hline Participant other race/ethnicity ${ }^{a}$ & 0.07 & 0.10 & 0.04 & 0.14 & -0.01 & 0.08 & -0.10 & 0.09 \\
\hline Participant economic pressure * participant commitment & - & - & - & - & 0.01 & 0.05 & -0.07 & 0.06 \\
\hline Participant economic pressure $*$ participant rel. maint. beh & - & - & - & - & -0.05 & 0.04 & -0.05 & 0.04 \\
\hline Participant economic pressure ${ }^{*}$ spouse commitment & - & - & - & - & $0.14 * *$ & 0.05 & 0.06 & 0.06 \\
\hline Participant economic pressure $*$ spouse rel. maint. beh & - & - & - & - & $-0.10^{*}$ & 0.04 & -0.06 & 0.05 \\
\hline $\mathrm{R}^{2}$ & 0.28 & & 0.27 & & 0.49 & & 0.41 & \\
\hline
\end{tabular}

$\mathrm{CFI}=0.95, \mathrm{RMSEA}=0.03, \mathrm{SRMR}=.01$

$* p<.05 ; * * p<.01 ; * * * p<.001$

${ }^{a}$ Only actor effects were controlled for with these variables

${ }^{\mathrm{b}}$ These were couple-level variables

Husbands' consumer debt was negatively associated with marital satisfaction $(b=-0.02, p<.05)$ while their liquid savings were positively associated $(b=0.02, p<.05)$. Hispanic husbands were more satisfied with their marriages than White, non-Hispanic husbands $(b=0.23, p<.001)$. We note that none of the interactions were significant predictors of husbands' marital satisfaction. The model explained $48 \%$ of the variance in husbands' reported marital satisfaction.

Table 3 shows the path model results for divorce proneness. Model fit for this model was also strong. The CFI was 0.95 , the RMSEA was 0.03 , and the SRMR was 0.01 .

The association between the independent variables and economic pressure shown in Table 3 were nearly identical to the results in Table 2, as would be expected, so we do not discuss them. Wives' reports of housing-related problems were positively associated with divorce proneness $(b=0.27, p<.01)$, even though economic pressure was also in the model. In fact, although wives' reports of economic pressure were positively associated with divorce proneness, the coefficient was small $(b=0.06, p<.05)$. Wives' reports of their own marital commitment $(b=-0.76, p<.001)$ and relationship maintenance behaviors $(b=-0.18, p<.001)$ and husbands' reports of their own marital commitment $(b=-0.22, p<.001)$ and relationship maintenance behaviors $(b=-0.22, p<.001)$ were all negatively associated with wives' reports of divorce proneness. Black, non-Hispanic wives reported more divorce proneness $(b=0.51, p<.001)$ than White, non-Hispanic wives.

Two interaction terms were associated with the wives' reports of divorce proneness. The first was a negative interaction between wives' economic pressure and husbands' relationship maintenance behavior $(b=-0.10, p<.05)$. Graphing the predicted wives' divorce proneness (Fig. 3) suggests that higher levels of husbands' relationship 
Fig. 3 Wives' predicted divorce proneness based on the wives' economic pressure by husbands' relationship maintenance behavior interaction

Fig. 4 Wives' predicted divorce proneness based on the wives' economic pressure by husbands' commitment interaction
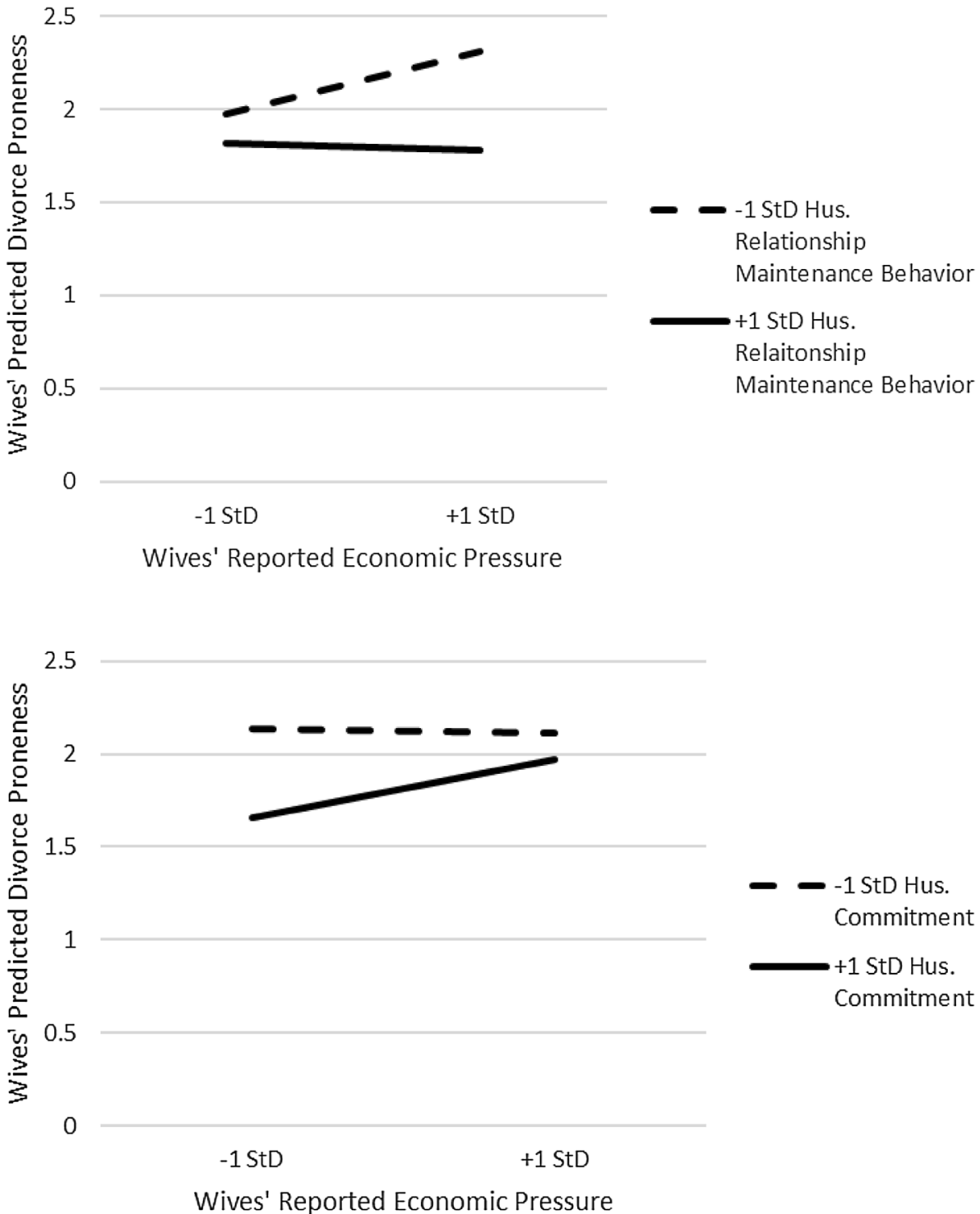

maintenance behaviors (+ 1 standard deviation) were associated with divorce proneness levels that were equal whether wives' reported low ( -1 standard deviation) or high $(+1$ standard deviation) economic pressure. Lower levels of husbands' relationship maintenance behaviors (- 1 standard deviation) were associated with higher levels of divorce proneness, though, when wives reported greater economic pressure (+ 1 standard deviation) than when wives reported less economic pressure ( -1 standard deviation).

The second interaction term was a positive interaction between wife economic pressure and husband commitment ( $b=0.14, p<.01)$. Graphing the predicted levels of divorce proneness (Fig. 4) showed that wives reporting lower levels of economic pressure ( -1 standard deviation) reported different levels of divorce proneness depending on their husbands' reported commitment (the difference was about 0.5 points and favored those with more committed husbands).
However, among wives reporting high levels of economic pressure (+1 standard deviation), the differences were not large in practical terms. The overall model explained $49 \%$ of the variance in wives' reports of divorce proneness.

In the husbands' models, husbands' economic pressure was positively associated with their reports of divorce proneness $(b=0.09, p<.01)$. As in the wives' models, husbands' commitment $(b=-0.65, p<.001)$ and relationship maintenance behaviors $(b=-0.20, p<.001)$ and wives' commitment $(b=-0.24, p<.001)$ and relationship maintenance behaviors $(b=-0.20, p<.001)$ were negatively associated with husbands' reports of divorce proneness. Black, nonHispanic husbands reported higher levels of divorce proneness than White, non-Hispanic husbands $(b=0.31, p<.01)$. None of the interaction terms were associated with husbands' divorce proneness. The model explained $41 \%$ of the variance in husbands' reports of divorce proneness. 


\section{Discussion}

We employed the Family Stress Model of Economic Pressure and Marital Distress (Conger et al. 1994) to examine whether commitment and relationship maintenance behaviors acted as marital resilience factors when participants reported feelings of economic pressure. Using a contemporary national sample of married couples, we found that employment- and housing-related problems during the 2007-2009 Recession were indirectly and directly related to the marital outcome variables. Furthermore, economic pressure was negatively associated with marital satisfaction and positively associated with divorce proneness. The only moderators that were significant were an interaction between wives' economic pressure and husbands' relationship maintenance behavior and an interaction between wives' economic pressure and husbands' commitment.

Husbands' relationship maintenance behaviors moderated the association between wives' economic pressure and wives' marital quality (both satisfaction and divorce proneness). We were not able to directly test the mechanisms in these relationships, but we do offer suggestions of possible mechanisms. One possible explanation for this finding is that husbands' relationship maintenance behaviors help to reduce wives' anxieties about economic pressure, thus helping maintain marital quality. Having the support of one's spouse may reduce some of the negative affect that frequently accompanies economic pressure (Conger et al. 1999).

However, relationship maintenance behaviors may also act as a visible signal of husbands' commitment to continuing the relationship. We had hypothesized that spouses who show that they are willing to invest in their marriage by serving their spouse may have better marriages despite economic pressure. Husbands who evidence their commitment by behaving in ways that sustain their relationship may help reduce their wives' anxiety about the status of the relationship-particularly when there are other problems such as financial issues.

Finally, the association may have resulted from simply meeting relationship expectations. Married individuals desire to receive relationship maintenance behaviors (Dainton 2000). Figures 2 and 3 suggest marital stability for wives whose husbands more frequently engage in relationship maintenance behaviors regardless of levels of economic pressure. These figures, then, may suggest that the "action of the story" may be occurring among the wives who received fewer relationship maintenance behaviors from their husbands. Even when they faced less economic pressure, these wives were less happy and more divorce-prone than their counterparts whose husbands engaged in more relationship maintenance behaviors. Adding economic pressure may have exacerbated the fact that these women were not realizing their relationship expectations, which may then decrease marital quality. Again, all three of these potential mechanisms need investigation before we can definitively settle on any of them as explanations.

The commitment finding also needs explanation. Contrary to our hypotheses, husbands' commitment was only associated with lower levels of wives' divorce proneness under conditions of lower levels of economic pressure. At higher levels of economic pressure, husbands' commitment was not associated with better levels of wives' divorce proneness. When wives face economic pressure, commitment (i.e., an attitude) might not be adequate to maintain stability; wives may need the actual relationship maintenance behaviors that motivate commitment.

The fact that only husbands' commitment and relationship maintenance behaviors served as moderators was unexpected. Of the four past investigations of moderators of economic pressure, gender differences were found in only one. Liker and Elder (1983) found that husbands who experienced income loss and had unstable personalities during the Great Depression reported greater marital conflict relative to husbands who experienced income loss but who had stable personalities. Liker and Elder suggested that the differences stemmed from the gendered provider role norms of the 1930s. Our data, which were contemporary, showed that the main effects of economic pressure on marital quality were the same for husbands and wives. Thus, it is unlikely provider role norms were responsible for the gender differences.

We can only offer speculation as to the reasons for these gender differences. Gender differences in the meanings of relationship maintenance behaviors may exist. In general, women use relationship maintenance behaviors more than men (Dainton and Stafford 1993). Furthermore, gendered family norms still place the onus of "emotion work," a construct implying behaviors similar to relationship maintenance behaviors, on women (Erickson 1993, 2005). However, husbands' performance of emotion work has demonstrated a significant relationship with wives' reports of their relationship quality (Erickson 1993). Thus, high levels of husbands' relationship maintenance behaviors may have had an association with wives' marital quality because husbands performed relationship maintenance behaviors less often or because it was less normative. When wives felt high levels of economic pressure, but husbands engaged in high levels of relationship maintenance behavior, wives may have appreciated their husbands' relationship maintenance behaviors even more. These speculations await further research.

This study has limitations. First, the data were cross-sectional. This shortcoming limited our ability to specify the directions of relationships, and we are not able to imply anything about causality. Thus, we have tried to be circumspect as we described and discussed the findings. Future research might use longitudinal data to see if interactions between 
economic pressure and commitment or relationship maintenance behaviors would predict changes in marital quality.

Second, we used self-reported data in this study. Participants may have reported higher levels of certain variables (e.g., marital quality, commitment) due to social desirability. Unfortunately, we were not able to test how social desirability may have influenced the findings. This limitation is somewhat mitigated by our use of multiple reporters and the APIM framework. That is, in some cases, husbands' reports of relationship maintenance behaviors served as moderators of the relationship between wives' economic pressure and marital quality. It would be more difficult for social desirability to operate across multiple reporters and partner effects.

Further, many of our variables were single-item measures (e.g., economic pressure, divorce proneness). We did not have the space in the survey to employ multiple items in some measures. We recognize the measurement error issue that stems from using single-item variables. Greater reliability might have resulted in more statistically significant findings-especially in the interaction terms. We argue, however, that because many of the single-item measures conformed with theoretical expectations (e.g., the stressors were positively associated with economic pressure, economic pressure was positively associated with the marital outcome variables), that the single-item measures were sufficiently reliable and valid. We submit that given the reliability issue, our findings might have actually been lower-bound estimates of the true relationships in our model.

Finally, we should qualify these conclusions by noting that the participants' data were collected soon after the 2007-2009 Recession. Consequently, these findings may be most relevant for or applicable to couples during macroeconomic shocks. The protective nature of husbands' relationship maintenance behaviors might apply to the financial stressors of the 2007-2009 recession specifically, or to macro-economic shocks more generally. This qualification needs future research.

\section{Conclusion}

Many married couples, if not most, will experience financial difficulties during their relationship. This study adds to four other studies that have demonstrated individual and marital factors that can help couples maintain their quality during these financial difficulties. It is unfortunate that so few studies have examined a question that influences many families. This study specifically showed that husbands' relationship maintenance behaviors were especially helpful in keeping wives' marital quality stable in spite of wives' feelings of economic pressure.

The fact that husbands' relationship maintenance behaviors (i.e., small giving behaviors) help their wives maintain stable marital quality when they feel economic pressure may seem somewhat prosaic or pedestrian. Rather than reducing the importance of these findings, however, the prosaic nature of relationship maintenance behaviors is actually a strength. Relationship maintenance behaviors are marital behaviors that any spouse can cultivate. It does not matter whether a spouse has high or low socio-economic status or whether they have been married a long or short time, for example. They can still practice these simple behaviors of showing respect and appreciation toward their spouse. These behaviors are simple and, in their application, couple specific. Thus, any spouse can actively engage in these positive behaviors such that when an economic difficulty does occur, they can protect their relationship quality.

Acknowledgements These data were collected using a grant funded by The Science of Generosity Initiative at the University of Notre Dame.

\section{Compliance with Ethical Standards}

Conflict of interest The authors declared that they have no conflict of interest.

Ethical Approval All procedures performed in studies involving human participants were in accordance with the ethical standards of the institutional and/or national research committee and with the 1964 Helsinki declaration and its later amendments or comparable ethical standards.

\section{References}

Archuleta, K. L., Britt, S. L., Tonn, T. J., \& Grable, J. E. (2011). Financial satisfaction and financial stressors in marital satisfaction. Retrieved from http://krex.ksu.edu.

Blomquist, D. (2012). Slideshow: 2012 foreclosure market outlook [website]. Retrieved from http:// www.realtytrac.com/content/news-and-opinion/ slideshow-2012-foreclosure-market-outlook-7021.

Conger, R. D., Ge, X. J., \& Lorenz, F. O. (1994). Economic stress and marital relations. In R. D. Conger \& G. H. Elder, Jr. (Eds.), Families in Troubled Times: Adapting to Change in Rural America (pp. 187-203). New York: Aldine De Gruyter.

Conger, R. D., Rueter, M. A., \& Elder, G. H. Jr. (1999). Couple resilience to economic pressure. Journal of Personality and Social Psychology, 76, 54-71. doi:10.1037/0022-3514.76.1.54.

Dainton, M. (2000). Maintenance behaviors, expectations for maintenance, and satisfaction: Linking comparison levels to relational maintenance strategies. Journal of Social and Personal Relationships, 17, 827-842. doi:10.1177/0265407500176007.

Dainton, M., \& Stafford, L. (1993). Routing maintnenace behaviors: A comparison of relationship type, partner similarity and sex differences. Journal of Social and Personal Relationships, 10, 255-271. doi: $10.1177 / 026540759301000206$.

Dew, J. P., Britt, S., \& Huston, S. J. (2012). Examining the relationship between financial issues and divorce. Family Relations, 61, 615-628. doi:10.1111/j.1741-3729.2012.00715.x.

Dew, J. P., \& Wilcox, W. B. (2013). Generosity and the maintenance of marital quality. Journal of Marriage and Family, 75, 1218-1228. 
Ellison, C. G., Henderson, A. K., Glenn, N. D., \& Harkrider, K. E. (2011). Sanctification, stress, and marital quality. Family Relations, 60, 404-420. doi:10.1111/j.1741-3729.2011.00658.x.

Erickson, R. J. (1993). Reconceptualizing family work: The effect of emotion work on perceptions of marital quality. Journal of Marriage and Family, 55, 888-900. doi:10.2307/352770.

Erickson, R. J. (2005). Why emotion work matters: Sex, gender, and the division of household labor. Journal of Marriage and Family, 67, 337-351. doi:10.1111/j.0022-2445.2005.00120.x.

Goodman, C. J., \& Mance, S. M. (2011). Employment loss and the 2007-09 recession: An overiew. Monthly Labor Review, 134, 3-12.

Johnson, D. R., \& Young, R. (2011). Toward best practices in analyzing datasets with missing data: Comparisons and recommendations. Journal of Marriage and Family, 73, 936-945. doi:10.1111/j.1741-3737.2011.00861.x.

Kenny, D. A., Kashy, D. A., \& Cook, W. L. (2006). Dyadic data analysis. New York: Guilford.

Kline, R. B. (2005). Principles and practice of structural equaion modeling (2nd edn.). New York: Guilford Press.

Liker, J. K., \& Elder, G. H. Jr. (1983). Economic hardship and marital relations in the 1930s. American Sociological Review, 48, 343 359. doi: $10.2307 / 2095227$.

Papp, L. M., Cummings, E. M., \& Goeke-Morey, M. C. (2009). For richer, for poorer: Money as a topic of marital conflict in the home. Family Relations, 58, 91-103. doi:10.1111/j.1741-3729.2008.00537.x.

Patterson, J. M. (2002). Integrating family resilience and family stress theory. Journal of Marriage and Family, 64, 349-360. doi:10.1111/j.1741-3737.2002.00349.x.

Stafford, L. (2003). Maintaining romantic relationships: A summary and analysis of one research program. In D. J. Canary \& M. Dainton (Eds.), Maintaining relationships through communication: Relational, contextual, and cultural variations (pp. 51-77). Mahwah, NJ: Lawrence Erlbam Associates.

Stafford, L. (2011). Measuring relationship maintenance behaviors: Critique and development of the revised relationship maintenance behavior scale. Journal of Social and Personal Relaitonships, 28, 278-303. doi:10.1177/0265407510378125.

Stafford, L., \& Canary, D. J. (1991). Maintenance strategies and romantic relationship type, gender, and relational characteristics.
Journal of Social and Personal Relationships, 8, 217-242. doi:10.1177/0265407591082004.

Stanley, S. M., \& Markman, H. J. (1992). Assessing commitment in personal relationships. Journal of Marriage and the Family, 54, 595-608. doi: $10.2307 / 353245$.

Stanley, S. M., Markman, H. J., \& Whitton, S. W. (2002). Communication, conflict, and commitment: Insights on the foundations of relationship success from a national survey. Family Process, 41, 659-675. doi:10.1111/j.1545-5300.2002.00659.x.

Stanley, S. M., Rhoades, G. K., \& Whitton, S. W. (2010). Commitment: Functions, formation, and the securing of romantic attachment. Journal of Theory and Family Review, 2, 243-257. doi:10.1111/j.1756-2589.2010.00060.x.

Wieselquist, J., Rusbult, C. E., Foster, C. A., \& Agnew, C. R. (1999). Commitment, pro-relationship behavior, and trust in close relationships. Journal of Personality and Social Psychology, 77, 942-966. doi:10.1037/0022-3514.77.5.942.

Wilcox, W. B., \& Dew, J. P. (2016). The social and cultural predictors of generosity in marriage: Gender egalitarianism, religiosity, and familism. Journal of Family Issues, 37, 97-118.

Jeffrey Dew is an Associate Professor in the School of Family Life at Brigham Young University. He received a dual-titled PhD in Human Development and Family Studies and Demography from The Pennsylvania State University. Dr. Dew's research focuses on the "daily life" issue of the association between family resources (i.e., money and time) and relationship quality. Examples of Dr. Dew's recent projects include examining factors that protect couples' marital quality during financial difficulties, and a qualitative strengths-based analysis of how African American couples talk about the role of finances in their marriage. Dr. Dew's research has won numerous award from academic journals and professional organizations.

Mark Jackson is a researcher and consultant in the Research Division of the Correlation Department in The Church of Jesus Christ of Latter-day Saints. He works on a number of research projects ranging from evaluating international curriculum materials to investigating faith development during various age groups. Dr. Jackson completed his PhD in Human Development and Family Studies at Utah State University. 